\title{
Metastatic primary anorectal melanoma developing in a patient treated for multicentric glioblastoma multiforme: two rare malignancies presenting in synchronicity
}

\author{
Irfan Ahmad, ${ }^{1}$ Irfan Bashir, ${ }^{1}$ Neeraj Dhingra, ${ }^{1}$ Vijay Hangloo ${ }^{2}$
}

${ }^{1}$ Radiation Oncology, Batra Hospital and Medical Research Centre, New Delhi, Delhi, India ${ }^{2}$ General Surgery, Batra Hospital and Medical Research Centre, New Delhi, Delhi, India

\section{Correspondence to}

Dr Irfan Ahmad,

irfan.a@icloud.com

Accepted 28 February 2018

\section{DESCRIPTION}

A 66-year-old woman presented with complaints of dizziness, headache and forgetfulness, which had been worsening over the last 2 months. General physical examination revealed weakness in the left upper and lower limbs (power 4/5) with spasticity (deep tendon reflexes $3+$ on left side). A non-contrast MRI brain revealed a mass lesion involving the right thalamus and another lesion in the right cerebellar peduncle. Both lesions were hyperintense

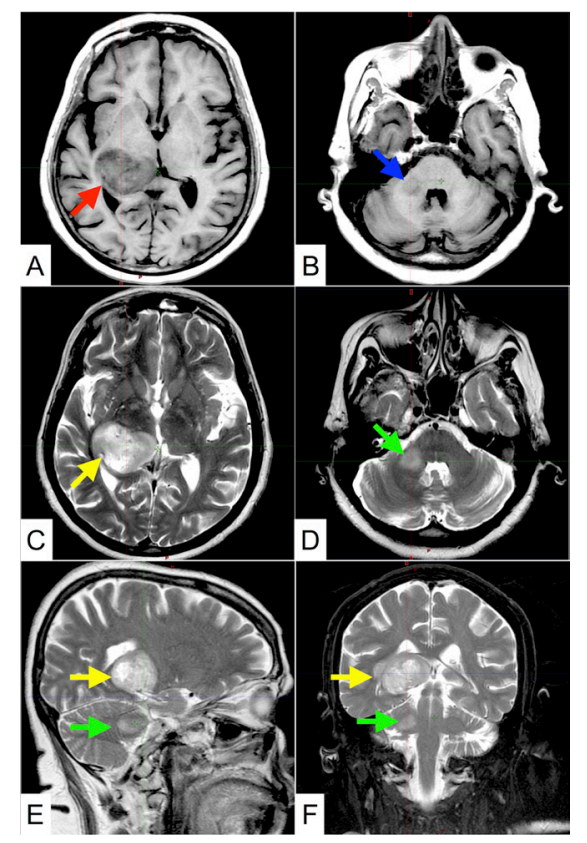

Figure 1 Pretreatment non-contrast MRI images of multicentric glioma. (A) T1-weighted axial image reveals a hypointense space-occupying lesion in the right thalamus involving the right basal ganglia (red arrow). (B) T1-weighted axial image reveals a hypointense space-occupying lesion in the right middle cerebellar peduncle (blue arrow). (C, D) T2-weighted axial image reveals the heterogeneously hyperintense nature of the lesions involving the right thalamus (yellow arrow) and right middle cerebellar peduncle (green arrow). Note the relative lack of extensive perilesional oedema. $(E, F)$ T2-weighted sagittal and coronal images demonstrate the discontinuity of both lesions, the right thalamic lesion located supratentorially (yellow arrow) and the right middle cerebellar peduncle lesion located infratentorially (green arrow).

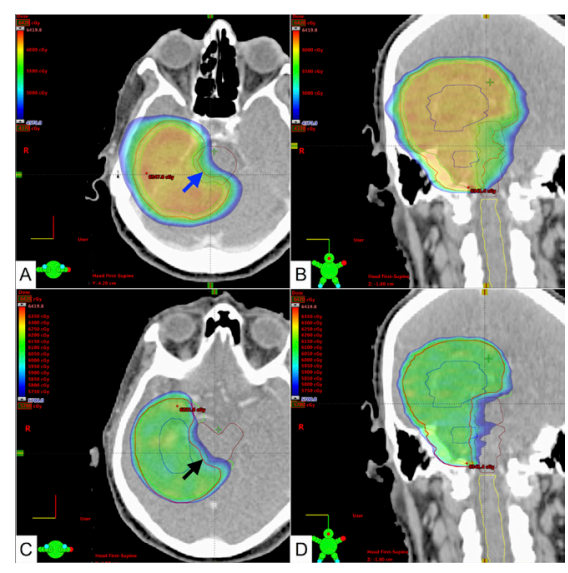

Figure 2 Treatment planning images. (A, B) Dose colour wash in the axial and coronal planes with the lower limit set to $95 \%$ of $46 \mathrm{~Gy}$. The planning target volume (PTV_46) was created by expanding the clinical target volume (CTV_46) by $3 \mathrm{~mm}$, as per our institutional protocol for image-guided treatment delivery. Note that the PTV for this dose level has been allowed to extend into the brainstem (blue arrow). The planning parameter was volume receiving $95 \%\left(\mathrm{~V}_{95 \%}\right)$ of the prescribed dose (46 Gy) should be more than $98 \%$. In this patient, the PTV_46V $\mathrm{V}_{95 \%}$ was $100 \%$. (C, D) Dose colour wash in the axial and coronal planes with the lower limit set to $95 \%$ of $60 \mathrm{~Gy}$. Note that the PTV for this dose level has been cropped from the brainstem (black arrow) to permit sparing of the brainstem. The planning parameter was to achieve maximum dose received by $1 \mathrm{cc}\left(D_{1 \mathrm{cc}}\right)$ of the brainstem to be less than $59 \mathrm{~Gy}$. In this patient, the $D_{1 \text { cc }}$ of the brainstem was $58.1 \mathrm{~Gy}$.

on T2 and hypointense on T1 sequences (figure 1). A stereotactic biopsy from the thalamic lesion revealed glioblastoma multiforme (WHO Grade IV) on histopathological evaluation and immunohistochemistry (Ki67 index: 15\%-20\%). Due to financial constraints, $\mathrm{O}(6)$-methylguanine-DNA methyltransferase(MGMT) promoter methylation status was not determined.

The case was discussed in our tumour board and keeping in view the similar radiological features and discontinuity of both lesions, a diagnosis of multicentric glioblastoma multiforme was made. ${ }^{1}$ The case was determined unresectable upfront and she was planned for concurrent chemoradiotherapy with image-guided volumetric modulated arc therapy and daily temozolomide $\left(75 \mathrm{mg} / \mathrm{m}^{2}\right){ }^{2}$ 


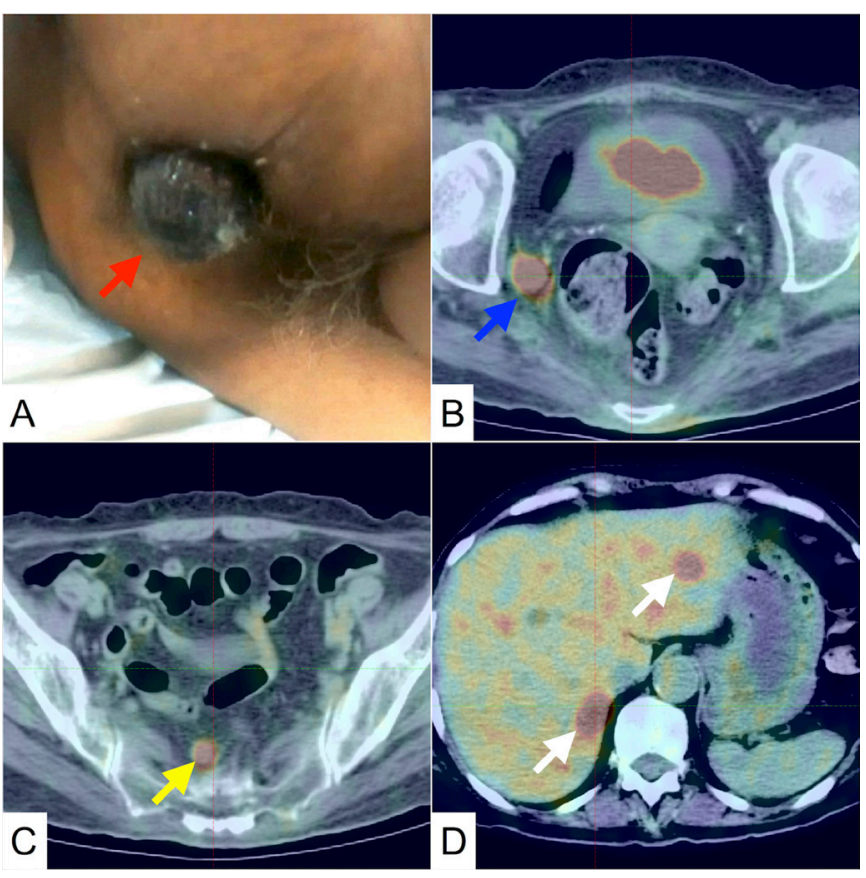

Figure 3 Images of the primary anorectal melanoma. (A) Physical examination finding with the patient in left lateral decubitus position with knees flexed towards the chest. A visible mass is seen protruding from the anal canal, with blackish discoloration on its surface (red arrow). This mass was reducible and painless in nature and considered a thrombosed grade III internal haemorrhoids. After excision, the size of the specimen was $5 \times 4 \times 2.5 \mathrm{~cm}$. (B, C, D) Axial PET-CT images showing disseminated FDG avid disease, in right internal iliac node (blue arrow), presacral node (yellow arrow) and hepatic metastases (white arrows).

She received 46 Gy in 23 fractions followed by a boost of 14 Gy in 7 fractions for a total dose of $60 \mathrm{~Gy}$ in 30 fractions (figure 2). The planning target volume was deliberately underdosed so as to respect the tolerance of the brainstem. Treatment planning and delivery were performed on Varian Eclipse v13.5 and Varian TrueBeam v2.5, respectively (Varian Medical Systems, Palo Alto, California, USA). Daily image guidance was performed with pretreatment cone beam CT or $\mathrm{kV}$ planar verification.

The patient tolerated treatment well without any interruptions. One month post-treatment completion, her symptoms started to resolve. She was advised to continue adjuvant temozolomide $\left(150 \mathrm{mg} / \mathrm{m}^{2}\right)$ monthly, and a repeat MRI brain done at 2 months post-treatment revealed stable disease with reduction of perilesional oedema.

A month later, she consulted a general surgeon for complaints of foul-smelling discharge per rectum and mass protruding from the anus. On examination, she was diagnosed with grade III internal haemorrhoids and note was made of blackish discoloration on its surface (figure 3). Wide local excision was performed and the excised specimen was sent for histopathological evaluation, which revealed primary anorectal melanoma. A staging whole-body ${ }^{18}$ flourodeoxyglucose positron emission tomography-CT $\left({ }^{18}\right.$ FDG PET-CT) revealed metastatic dissemination (multiple hepatic lesions, perirectal and presacral lymph nodes) (figure 3). The patient was planned for immunotherapy with intravenous nivolumab $240 \mathrm{mg}$ every 2 weeks and she received 4 cycles of the same. A week after the fourth cycle of nivolumab, the patient had a myocardial infarction and succumbed to it. The cause of death was deemed to be unrelated to cancer or its treatment. The case was discussed in our institutional multidisciplinary mortality meeting, and keeping in mind the advanced stage of melanoma at presentation, it was deemed that it likely developed synchronously with the multicentric glioma.

Multicentric gliomas are a rare entity, accounting for 2\%-16\% of all gliomas. ${ }^{2}$ Primary anorectal melanoma is also an exceedingly rare entity, accounting for $1 \%$ of all melanomas. ${ }^{3}$ To the best of our knowledge, this is the first reported instance of these two malignancies developing in a synchronous manner.

\section{Learning points}

Multicentric glioma, being a rare entity, is a diagnosis of exclusion, and distinction needs to be made between multifocal and multicentric gliomas.

- Primary anal melanoma is also an exceedingly rare entity and has a poor prognosis, with limited therapeutic options.

- Symptoms arising in another organ system in patients with glioblastoma multiforme should be investigated thoroughly and managed expeditiously, to maximise quality of life.

Contributors IA is the treating junior consultant (radiotherapy), author of the paper, responsible for drafting the manuscript and revising it. He is the guarantor. $\mathrm{IB}$ is the supervising treating consultant (radiotherapy) and participated in article formulation, editing and oversight. ND is the treating resident (radiotherapy) and participated in article formulation and editing. $\mathrm{VH}$ is the supervising treating consultant (general surgery) and participated in article formulation, editing and oversight.

Funding This research received no specific grant from any funding agency in the public, commercial or not-for-profit sectors.

Competing interests None declared.

Patient consent Obtained.

Provenance and peer review Not commissioned; externally peer reviewed.

(C) BMJ Publishing Group Ltd (unless otherwise stated in the text of the article) 2018. All rights reserved. No commercial use is permitted unless otherwise expressly granted.

\section{REFERENCES}

1 Batzdorf U, Malamud N. The problem of multicentric gliomas. J Neurosurg 1963;20:122-36.

2 Gondi V, Vogelbaum MA, Grimm S. Primary intracranial neoplasms. In: Halperin EC, Brady LW, Wazer DE, Perez CA, eds. Perez \& Brady's principles and practice of radiation oncology. 6th ed. Philadelphia: Lippincott Williams \& Wilkins, 2013:649-76.

3 Thibault C, Sagar P, Nivatvongs S, et al. Anorectal melanoma-an incurable disease? Dis Colon Rectum 1997;40:661-8. 
Copyright 2018 BMJ Publishing Group. All rights reserved. For permission to reuse any of this content visit http://group.bmj.com/group/rights-licensing/permissions.

BMJ Case Report Fellows may re-use this article for personal use and teaching without any further permission.

Become a Fellow of BMJ Case Reports today and you can:

- Submit as many cases as you like

- Enjoy fast sympathetic peer review and rapid publication of accepted articles

- Access all the published articles

- Re-use any of the published material for personal use and teaching without further permission

For information on Institutional Fellowships contact consortiasales@bmjgroup.com

Visit casereports.bmj.com for more articles like this and to become a Fellow 